\title{
Num mundo em evolução rápida e turbulenta, as ciências sociais em questão
}

\author{
José Rodrigues dos Santos
}

\begin{abstract}
Resumo
Neste texto 0 autor interroga o lugar das Ciências Sociais (CS) num mundo que outorga cada vez mais um privilégio absoluto às tecno-ciências, à "Big Science", e às suas aplicações tecnológicas. A tese exposta é a de que as mudanças que o mundo actual conhece colocam, pela sua profundidade e pela velocidade a que se operam, um desafio às nossas sociedades que só as CS podem sustentar: o da compreensão e da condução dos processos de transformação social e das suas consequências. Para responder ao desafio, as CS devem desenvolver uma dupla estratégia científica: ao nível epistemológico, a de elaborar os conceitos e os instrumentos de investigação, e ao nível do ensino, nomeadamente ao nível superior, fomentar uma aprendizagem criteriosa das CS, inserindo-as nos currículos. Os objectivos serão o de fundar uma nova "cultura geral" dos cidadãos, e o de produzir conhecimento operacional em benefício das políticas de desenvolvimento económico, social e humano das nossas sociedades.
\end{abstract}

\section{Palavras-chave}

Ciências Sociais; Mudança; Currículos; Epistemologia; Investigação; Ensino; Políticas Sociais

\section{Da utilidade social das ciências Sociais (CS) às utilidades do seu ensino}

Não é necessário expor aqui, como o fizeram tantos outros antes de nós, e bem, os contributos das Ciências Sociais para o conhecimento das sociedades sobre elas próprias. Mas este conhecimento pode entender-se em vários planos que, apesar de serem conexos, colocam problemas diferentes. Se tomarmos este conhecimento no sentido geral e teórico, a sua utilidade é raramente imediata, porque ele representa precisamente uma ferramenta para produzir conhecimentos mais específicos sobre objectos empíricos limitados. Para utilizar uma metáfora industrial, esse conhecimento teórico fundamental é 
como a fábrica que produz máquinas que serão utilizadas nas fábricas de que saem produtos de consumo corrente. É a fábrica dos teares automáticos, esses mesmos que depois irão servir para produzir os panos de algodão ou lã. Mas é claro que os "teares" são concebidos para satisfazer funções técnicas especiais, diferentes das prensas de metais que são concebidas e fabricadas para a indústria automóvel. Por outras palavras, os saberes teóricos das ciências em geral e das Ciências Sociais em particular têm 0 dever de pensar as necessidades de campos de saber que estão fora delas, e estes campos de saber são também campos de actividades sociais: profissionais, culturais, políticas, etc.

A produção de conceitos e de instrumentos de conhecimento pelas Ciências Sociais (CS) deve ter como horizonte a sua inserção nas práticas sociais, políticas, económicas, artísticas, e este objectivo deve ser pensado segundo duas modalidades. A primeira é a da análise das realidades profissionais que estruturam a actividade social e da sua cuidadosa descrição; a segunda éa da formação dos profissionais dos diversos domínios de modo a que eles possam mobilizar para as suas práticas os conhecimentos específicos produzidos pelas CS, ou seja: produzir saber sobre os contextos e as práticas profissionais e formar os profissionais para a utilização desse saber. Para além da sensibilização ao facto que não existe contexto técnico, por mais estritamente técnico que pareça, que não seja ao mesmo tempo contexto social, essa formação deve portanto ainda prosseguir outros objectivos mais específicos.

Mas antes de examinar esses contextos específicos, convém insistir sobre um tipo de utilidade das CS que nem por ser genérica e quase... invisível, deixa de ter uma enorme influência na eficiência global das sociedades, nos planos económico, político e social.

\section{0 efeito "cultura geral"}

Com efeito, a formação dos cidadãos, futuros profissionais, qualquer que seja o ramo em que venham a desenvolver a sua actividade, é um dos aspectos particulares da utilidade das CS que aqui mais directamente nos interessam.

A questão tem vindo a impor-se cada vez com mais acuidade nos últimos anos. Os novos profissionais, nomeadamente aqueles que, pela alta qualificação que thes é exigida, são chamados a exercer funçōes de direcção, são cada vez menos originários das classes sociais mais favorecidas, que há apenas algumas décadas atrás preenchiam de modo "natural" esses cargos. A formação científica e técnica de cariz profissional que esses jovens recebiam era precedida por currículos (das escolas primárias e secundárias) nos quais as matérias pertencentes ao domínio das humanidades ocupavam um lugar de destaque e, mais importante ainda, eram transmitidas de modo informal nos contextos familiares. 0 futuro engenheiro não se tornava um dirigente apenas em virtude do saber técnico específico da sua futura profissão, mas talvez mais ainda, pelo saber lidar com os meios sociais diversos, com os outros dirigentes, com a política, com a cultura em geral. Os saberes tácitos, ou implícitos, nos quais assentava o exercício das profissões eram uma herançă"natural" dessas classes.

Paradoxalmente, à medida que os contextos económicos (a sociedade pós-industrial, a globalização) sociais (sociedade da informação e depois do conhecimento), políticos (progresso e crise das 
democracias), se iam tornando mais complexos, mais voláteis, os profissionais técnicos viram as suas formações tornar-se mais fechadas, mais estreitas, mais isoladas da cultura comum. E esses profissionais já não trazem "de casa" os instrumentos de interpretação do mundo que Ihes era dado pelas Humanidades e pelas Artes. Os técnicos são mais estreitamente (e não só estritamente) técnicos, a sua percepção dos efeitos das suas decisões e acções é menos clara, a sua visão quanto aos futuros alternativos possíveis (nos quais eles têm uma parte de responsabilidade) é mais estéril. Do positivismo à ilusão de que "não há alternativas", nem no domínio tecnológico a longo prazo, nem nos modos de organização da actividade económica, nem nos modos de relacionamento entre cidadãos e Estados, há apenas um passo: 0 que consiste em transferir uma epistemologia positivista simplificada do domínio profissional para as sociedades a que pertencem.

Ora, o que as CS constituem hoje para um número crescente de cidadãos é precisamente uma nova "cultura geral", que ocupa em parte o espaço deixado livre pela decadência das disciplinas clássicas da cultura do século XIX e início do século XX, humboldtiano e napoleónico: Latim e Grego, Filosofia e Teologia, Filologia, História da antiguidade, História da Arte, Literatura.. . .

Autores como Bernard Lahire, Philippe Corcuff, Robert Castel, François de Singly num volume colectivo [Lahire 2002], insistiam na ideia de que a função da "cultura geral"do nosso tempo é preenchida pelas CS. 0 Ciclo de Conferências "Sociologia, Ciência e Profissão" tentou, em Portugal, responder ao mesmo desafio [Resende 2003].

A par com o desenvolvimento de cada uma das disciplinas particulares que constituem o campo das CS (Sociologia, História, Antropologia, Psicologia Social, Economia, Demografia, etc.) e, no interior de cada uma delas, do aprofundamento das especialidades, existe, pois, uma base comum, que é, antes de mais, epistemológica: uma certa relação com o saber. Se é verdade que as CS estão destinadas a ser a "cultura geral" dos novos tempos, então elas têm que conservar o que delas faz saberes gerais, ou seja, saberes do particular e da sua múltipla articulação com os outros saberes particulares e com o saber geral que visam, que mais não é do que conhecer os fundamentos do conjunto do campo dos saberes científicos. Acresce que, ao desenvolverem os seus objectos específicos, as CS não podem perder de vista a coexistência permanente, inevitável e fundadora, da multiplicidade dos ângulos de observação e dos quadros interpretativos, o que as prepara para transmitir a relação com o saber e a dúvida que são os fundamentos do espírito científico, em qualquer domínio em que ele se exerça.

Considerando as consequências dessa função no que diz respeito ao ensino das CS, importa salientar a necessidade, aliás sentida por todos os docentes que tiveram algum dia que leccionar uma unidade curricular de CS, de definir objectivos específicos da cadeira, não só em função da utilidade genérica acima evocada, mas também de acordo com a utilidade prática que dela se espera para 0 contexto global da formação, cujo núcleo principal pertence frequentemente a outros campos profissionais. Esta preocupação significa que não só, como muitas vezes acontece, os exemplos ilustrativos da matéria sejam escolhidos tendo em conta a formação em que a ICS se integra, o que é um requisito mínimo, mas mais do que isso, os próprios conteúdos, o entrosamento das questões, das teorias, das ferramentas teóricas das CS, sejam repensados em função dos objectivos da formação de que faz parte e da realidade concreta do desempenho profissional quie os espera. Como veremos, a relação entre 
uma unidade curricular de ICS e o restante plano curricular não só não é constante, como não tem definição a priori, válida em todos os contextos.

Cada plano curricular, e sobretudo os que estão mais cristalizados em volta de opções tradicionais, pode tirar um benefício diferente de uma componente em CS. Se a explicitação da "dimensão social", recorrendo às palavras de Marc Augé [1984] de cada uma das grandes esferas de actividade profissional (engenharias, medicinas, literaturas, ciências militares), constitui, de facto, uma preocupação comum em todas elas, na realidade, a prossecução desse objectivo genérico exige abordagens bastante diversas consoante as formações. Em cada uma das esferas profissionais estruturadas (e organizadas em instâncias corporativas), desenvolveu-se uma cultura particular. Esta rege as maneiras de encarar o exercício das profissões, mas também - e é sobretudo o que nos interessa pois é uma utilidade imediata, que deveria produzir efeitos ainda no decurso da formação inicial - uma relação sui generis com o saber, com a autoridade estabelecida no domínio dos conhecimentos profissionais, com a inovação, com os próprios objectos de conhecimento e, nas profissões aplicadas como a Medicina ou as engenharias, com os objectos de acção.

Na maior parte dos casos, podemos sugeri-lo, o papel de uma componente de CS consiste principalmente em demonstrar aos alunos que a epistemologia positivista espontânea, ingénua, que serve de cultura científica a muitos futuros e actuais profissionais, não permite abarcar a complexidade não só dos problemas derivados da inserção social das actividades profissionais, mas também da acção propriamente técnica.

Introduzir a dúvida e demonstrar a necessidade da reflexão que tende a não aceitar como dados uma vez por todas os resultados anteriormente adquiridos, introduzir a necessidade de conhecer e combinar diversos pontos de vista sobre um mesmo objecto, abrir a consciência para o facto que se os saberes têm uma história, esta não acabou, é menos linear do que parece e envolve tanto factores propriamente cognitivos como factores sociais, que os torna contingentes a uma época e a uma sociedade. As ICS devem ser unidades curriculares que, a0 apresentar-se à primeira vista como cadeiras de "cultura geral" (expressão que, significativamente, se tornou pejorativa!), têm por missão introduzir... uma atitude crítica, reflexiva (visto que ela incide sobre a própria prática), e dar instrumentos de contextualização intelectual, sem os quais o Engenheiro é um simples produtor de artefactos, o Médico um reparador de corpos, o Arquitecto um fabricante de objectos destinados a alojar indivíduos abstractos.

\section{Lugar das Ciências Sociais nos planos curriculares}

Temos consciência que um dos recursos que mais crucial seria para a reflexão sobre a utilidade do ensino das CS no seio dos planos do conjunto dos estudos superiores e por consequência, sobre as orientações que conviria adoptar, tanto num plano geral como em cada um dos principais tipos de situações, a saber, um inventário de todos os planos de cursos que actualmente incluem (ou incluiram no passado próximo), um ensino introdutório às (S (v.g. uma cadeira de ICS), não está ao 
nosso alcance. Uma prospecção que encetámos, a nível mundial, mas permanece muito incompleta, forneceu-nos uma lista bastante longa de formações que integram uma ICS, de que fazem parte:

- A Arquitectura;

- A Medicina;

- Certas engenharias;

- A Economia, a Gestão;

- Certas formações de professores dos ensinos básico e secundário.

- Nas formações de Oficiais das Forças Armadas;

- Nas licenciaturas com mais afinidades com as CS, como sejam a História, a Psicologia ou a Filosofia, os ensinos introdutórios (ICS) estão geralmente presentes, ou são substituídos por uma Introdução a uma das disciplinas das CS (Antropologia, Sociologia, etc.).

- Nas licenciaturas de índole literária ou linguística, é raro que esteja incluída uma ICS. Do quadro de conjunto destacam-se vários traços notáveis.

- Se bem que algumas formaç̃ões tendam, na maioria das escolas, a incluir uma ICS, tal opção é raramente universal (é o caso dos cursos de Economia, de Gestão, de Arquitectura, de Psicologia).

- Algumas formações parecem tender para uma tomada em consideração do contributo das CS, mas tal progressão parece ser lenta (caso da Medicina, pois alguns cursos há muito incluem ICS, mas não parece ter-se tornado prática dominante).

- Outras formações parecem avessas à utilidade das (S; umas são de índole técnica (engenharias), outras de cariz humanístico (literaturas, línguas). As escolas que fazem excepção são ainda muito minoritárias.

Entretanto, o estudante das matérias técnológicas acima evocadas, quando induzido a adoptar uma atitude passiva perante os saberes como a que tendem (por vezes involuntariamente) a veicular as profissões regulamentadas, técnicas, nas quais a autoridade da coisa "sabida"e ensinada parece intocável, torna-se um mau estudante.

É certo que a integração de um ensino introdutório às CS, como o que aqui nos serve de referência, não deveria representar a totalidade do contributo das CS para as diferentes formações. Pelo contrário, uma Introdução, se é verdade que deve ter em conta o contexto científico da formação na qual se integra, deveria também preocupar-se com o seu próprio prolongamento no decurso da mesma formação, em termos de unidades curriculares de CS que dela participam.

\section{Dois objectivos fundamentais de uma ICS: Um panorama e con- ceitos e métodos}

Muitas ICS não têm qualquer continuação nos planos curriculares: são uma simples sensiblização a um vasto universo intelectual, sem outras ambições, porque sem continuidade ou aprofundamento. Este é sem dúvida um caso extremo, mas não tão raro quanto pareceria normal. 
Outras, pelo contrário, são o ponto de partida para a aquisição de um número mais ou menos importante de unidades, que constituem uma componente de peso (que pode ultrapassar um terço do total), em planos curriculares que não se definem como pertencendo ao campo das (S. Entre os dois extremos, todas as figuras intermédias existem. Por seu turno, a experiência precedente dos estudantes no domínio das CS é um factor limitante de primeira importância, como veremos a seguir, na secção dedicada à implementação do ensino de uma ICS.

A consideração destes dois parâmetros em simultâneo determinará por um lado, o equilíbrio que convém instaurar entre o"panorama" e a exposição de "conceitos e instrumentos" e por outro, guiará a escolha, no interior do "panorama", das disciplinas que serão ou não abordadas e o grau de aprofundamento que convém a cada uma delas.

\section{Condições de implementação de um ensino introdutório às CS}

É pois nossa ideia que a concepção dos objectivos e dos conteúdos programáticos da cadeira deve ajustar-se a dois parâmetros: a posição das CS no currículo do curso universitário, e a competência previamente adquirida neste domínio no âmbito do ensino secundário. Cada um destes dois parâmetros deve ser considerado enquanto factor em parte independente do outro, ao conceber o ensino de ICS. Se quisessemos esquematizar os tipos de situações que correspondem às modalidades extremas dos dois parâmetros, obteríamos uma matriz como a que desenhamos nas páginas que seguem.

\subsection{Tipos de posições das CS nos currículos}

Do cruzamento das duas variáveis obtemos dois casos extremos, com os valores positivos nas duas variáveis ou negativos também nas duas. No primeiro tipo de situações (caso no 1), os al unos possuem uma preparação prévia (seja porque frequentaram disciplinas específicas que abrem o acesso a cursos superiores que incluem as $(S$, seja, mais genericamente, por terem escolhido uma secção do ensino secundário que inclui uma ou várias (S ou disciplinas das Humanidades), e o plano de estudos do curso superior em que estão inscritos prevê outras unidades curriculares de $C S$, após a Introdução.

No caso simétrico (caso n² 2), também homogéneo nas duas variáveis, os alunos não usufruiram de qualquer preparação prévia (ou tiveram-na mas ela foi em absoluto insuficiente), e os seus cursos não prevêm outras unidades de $C S$, ou em número e com peso apenas residuais.

Nos casos de tipo 1, que correspondem em geral a cursos com fortes componentes de CS que exigiam formação prévia e o ensino pode sem dificuldade construir-se a um nível característico do ensino superior e adoptar objectivos ambiciosos porque os fundamentos que oferece serão explicitados, especificados em unidades curriculares sucessivas. A elaboração do programa definitivo a partir do esquema geral aqui sugerido deverá obedecer à preocupação de não repetição de matérias (quando, por exemplo, o currículo prevê uma "introdução à História"e/ou uma "introdução à Linguística", torna-se 
necessário reduzir o espaço ocupado por estas duas disciplinas no "Panorama", ou até eliminá-las, em benefício de um tratamento mais denso das restantes). Poderá por vezes acontecer que, estudado 0 currículo de uma determinada licenciatura à qual será dada uma ICS, concluamos que a aproximação que propomos em termos de história das ciências permaneça útil (assim, numa licenciatura em Economia cujo currículo não inclui nenhuma cadeira de história do pensamento económico, pode ser benéfico dar um esboço da formação da disciplina, nos seus aspectos teóricos e sociais, situados no contexto intelectual, social, político da época.

\begin{tabular}{|l|l|l|}
\hline $\begin{array}{l}\text { Posição no currículo } \\
\text { Competência prévia }\end{array}$ & $\begin{array}{l}\text { ICS prolongada no curso superior } \\
\text { por outras unidades de CS }\end{array}$ & $\begin{array}{l}\text { ICS NÃ0 prolongada no curso } \\
\text { superior por outras unidades de CS }\end{array}$ \\
\hline Formação secundária em CS & $\begin{array}{l}\text { 1. Nível inicial superior } \\
\text { Articulação com unidades } \\
\text { que seguem }\end{array}$ & $\begin{array}{l}\text { 3. Nível inicial superior } \\
\text { Unidade autosuficiente }\end{array}$ \\
\hline $\begin{array}{l}\text { Ausência de formação } \\
\text { secundária em CS }\end{array}$ & $\begin{array}{l}\text { 4. Nível inicial elementar } \\
\text { Articulação com unidades } \\
\text { que seguem }\end{array}$ & $\begin{array}{l}\text { 2. Nível inicial elementar } \\
\text { Unidade autosuficiente }\end{array}$ \\
\hline
\end{tabular}

0 caso no 2 coloca um problema muito diferente. Ele corresponde a cursos de cariz tecnológico ou das chamadas "ciências exactas" que, em circunstâncias extremas (mas frequentes), não oferece qualquer prolongamento à ICS, não podendo esta, por acréscimo, laborar na base de aquisições anteriores.

Uma ICS autosuficiente, isolada, é uma cadeira que corre o risco de ser reduzida a um ensino de"cultura geral", na pior e não na melhor das acepções e a ser percepcionada pelos alunos como uma perda de tempo. Os alunos tendem a não entender qual a utilidade da ICS, porque a posição que ela ocupa no currículo é incoerente e/ou não articulada com a restante formação. 0 desafio principal com que se defrontam os docentes é, em casos deste tipo, o de demonstrar de maneira perceptível, a alunos cuja falta de interesse inicial é profunda, que as CS Ihes permitem melhor exercer os seus futuros ofícios; com a condição de não contar apenas com o que pode ser adquirido numa única cadeira semestral, ou seja, se esta for percepcionada como um contacto que abre, fornecendo pontos de entrada, para um trabalho individual.

Os casos não homogéneos quanto às duas dimensões colocam problemas distintos. Admitimos que 0 caso n ${ }^{0} 3$ seja raro: os estudantes tiveram formação às $C S$ no secundário, mas a ICS encontra-se isolada no currículo que escolheram. Ele poderia corresponder a certas formações que, pertencendo embora ao domínio das CS no sentido lato, tendem a encarar-se como quase exclusivamente técnicas (como podem ser certos cursos de gestão) ou de natureza técnica e normativa (direito), que voltam as costas à natureza social dos seus objectos e por isso vêm as CS como inúteis (gestão) ${ }^{1}$ ou perigosas

10 facto de as formações à gestão ignorarem com frequência as CS, não prevendo a sua inclusão em lugar de destaque nos currículos corresponde ao que denunciam David, Hatchuel e Laufer [2000], a examinar "os novos fundamentos das ciências da gestão", investigando a epistemologia da investigação em gestão ("management"). É o que critica também Maugeri [2001], numa obra alusivamente intitulada "Delito de Gestão"; 0 "delito" consiste na apresentação da gestão como um domínio estritamente técnico, ocultando os processos sociais (negociação, regulação, poder, etc.). 
(direito). A inserção de uma ICS nestes currículos é, frequentemente, um sinal de abertura do corpo docente à problematização sociológica, que indicia uma atitude favorável à contextualização das práticas especializadas. Nestes casos, o programa de ICS, ao integrar as preocupações do núcleo principal dos cursos, poderá desenvolver, no "panorama", certos aspectos da psicologia social e da sociologia ou da filosofia, de modo a sensibilizar os alunos para aspectos da vida das organizações (gestão) ou da criação das normas sociais (direito), de modo a limitar a tendência que os alunos manifestam para uma redução ingenuamente positivista de um ensino já por si marcado pela mesma inclinação (mesmo quando este possui algum recuo crítico em relação ao realismo positivista).

0 caso n. ${ }^{4} 4$ é interessante pelo desafio que obriga a ICS a assumir: os alunos não possuem preparação prévia, o que exige um nível inicial muito modesto mas existem perspectivas de aprofundamento no âmbito do curso, o que incita a encarar a ICS como preparatória, tendo em vista os desenvolvimentos consecutivos. À primeira vista, tais situações deveriam corresponder a fases de transição na concepção de conjunto dos planos curriculares. Com efeito, a ausência de preparação prévia indica que o perfil do curso é percepcionado (com razão ou sem ela), como pertencendo a um campo científico que não se define pela presença de $C S$, o que explica que as opções que a ele conduzem e as disciplinas específicas que exige não incluam a obrigatoriedade de formação prévia em CS. Nos casos deste tipo, a questão pedagógica resolver-se-á examinando quais os requisitos que pressupõem as disciplinas do campo das CS que integram as fases seguintes do currículo. A ICS deveria portanto colocar-se ao serviço dos objectivos de aprofundamanto e das suas modalidades, ao "preparar o terreno" de modo coerente com o ensino que segue. É verosímil que a composição do "panorama" possa ser profundamante repensada, que o equilíbrio entre "panorama" e"conceitos e instrumentos" seja modificado em benefício de uma ou de outra componente (e o reequilibrio far-se-á, previsivelmente, em princípio em benefício da segunda).

Mas os dois casos que preenchem a linha inferior (ausência de formação prévia) colocam 0 projecto de leccionação de uma ICS perante uma evidência: se a cultura geral dos estudantes for fraca, e a preparaçãa específica (escolar) às CS ausente, torna-se praticamente impossível efectuar um trabalho de nível superior, de cariz propriamente universitário. Não se concebe que uma ICS que descreve, por exemplo, a formação da História ou da Geografia, dos seus conceitos e dos seus problemas, a um nível universitário, possa ser ensinada a alunos que desconhecem o significado (ainda que aproximado) de expressões tais como "Antiguidade clássica", "Idade Média", ou ainda "Reforma", para não mencionar que, Portugueses, ignoram o significado de datas tais como"1 de Dezembro", "1640", ou do termo "Restauração", ao mesmo tempo que, Europeus, são incapazes de mencionar os quinze países que até há pouco formavam a União Europeia e confundem países Bálticos com Balcãs.

Suspeitamos que um inquérito aos alunos oriundos das opções "Ciências" (!) ou Tecnologias mostraria que cerca de 80\% são incapazes de pensar a partir de periodizações históricas de base, de compreender conceitos elementares, talvez mesmo de elaborar um texto coerente sobre a matéria de uma aula de ICS. Tal realidade, ineludível, deve ser encarada de frente. Conceber um ensino para alunos 
ideais seria um erro tanto mais grave que as lacunas que se trata de contribuir para preencher são um importante factor de insucesso profissional ${ }^{2}$.

No primeiro caso típico acima referido (caso n. ${ }^{\circ}$ 1), a ICS deveria, sem dúvida, ter uma ambição panorâmica, sensibilizando os estudantes para um acervo de saberes, de interesses, de problemas, dos quais nenhum pode ser examinado em profundidade, mas se apoia em saberes elementares já adquiridos. 0 objectivo de fundo seria, então, efectuar com os estudantes um percurso através de um domínio de recursos intelectuais, cuja exploração lhes será facilitada, no futuro, pelo "guia" que constituiu a ICS. No segundo, a ICS, implementada em bom nível, por beneficiar de aquisições anteriores, anticipa sobre as unidades curriculares de CS que intervêm num ponto mais avançado dos estudos, fornecendo conhecimentos que servem de pano de fundo (nomeadamente quanto à história da formação das diversas disciplinas do campo das (S) e instrumentos metodológicos e epistemológicos de base (vocabulário, conceitos, métodos de raciocínio).

Os casos de tipo n. ${ }^{0}$, semelhantes aos que precedem no que concerne à preparação anterior, diferem quanto à posição no currículo, que é, desta feita, isolada, e exigem uma formulação diferente dos objectivos. Podemos, de facto, admitir que uma unidade curricular de CS única num currículo que compreende um total de 50 a 60 unidades, necessita, se o resultado que se procura atingir for mais ambicioso que acrescentar uma gota de cultura geral a um oceano de formação, uma adaptação à situação extrema em que se encontra seguindo duas linhas de referência. A primeira diz respeito à tomada em consideração do universo profissional ao qual se destinam os estudantes do curso; a segunda à escolha dos conceitos e instrumentos sobre os quais incide o ensino.

\subsection{Consequências para a implementação dum ensino introdutório às CS}

Sabendo embora que ao fazê-lo cometemos o pecado mais banal que mancha todas as propostas de unidades curriculares - pensar que a cadeira que regemos deve ser dotada de mais tempo e recursos, dada a sua importância... - o facto é que a opção por uma única cadeira semestral de ICS se revela frustrante para os docentes como para os estudantes. Com efeito, para a maior parte dos nossos estudantes e sem dúvida de maneira mais gritante para os que escolheram as opções "científicas" no ensino secundário, é indispensável que se consagre tempo suficiente a um Panorama das CS. Uma visão de tipo "enciclopédico", apenas moderada pela escolha adaptada a cada curso, de um leque parcial de disciplinas. Ora, este leque, por muito parcial que seja, para preencher os objectivos de alargamento de perspectivas e de sensibilização à diversidade e às modalidades de desenvolvimento

2 A título de exemplo, podemos reflectir sobre o pedido, formulado por uma grande escola portuguesa de engenharia, em Lisboa, para que sejam oferecidos aos alunos avançados e final istas seminários de "cultura geral". Não nos choca que se pense que a cultura geral desempenha um papel decisivo na capacidade profissional global dos engenheiros (e em particular influa no perfil dos que acedem a cargos de responsabilidade); choca-nos que se imagine "resolver" o problema com um ou dois "seminários" de uma semana, na fase final do curso. Ignora-se assim a natureza do problema de fundo e a utilidade das CS enquanto portadoras de uma componente não especializada, durante a própria formação, não após, nem mesmo no fim dos cursos. 
dos pontos de vista, e à sua complementaridade, nunca pode abranger menos que cinco ou seis disciplinas ${ }^{3}$. Se contarmos com um semestre de 14 a 15 semanas, e com uma hora de aulas teóricas por semana ${ }^{4}$, poderíamos consagrar 3 horas de apresentação teórica a cada uma de 5 disciplinas, por exemplo: História, Geografia, Psicologia, Demografia, Economia; ou ainda: História, Economia, Filosofia, Antropologia, Sociologia; etc. Por um lado, pois, não é razoável renunciar a apresentar um leque minimamente variado de disciplinas, a fim de conseguir fazer surgir a questão da diversidade e da articulação dos pontos de vista, a partir de material exposto. Por outro, torna-se frustrante e talvez inútil, se não contraproducente, consagrar um tempo demasiado curto a cada disciplina, correndo o risco de, pela superficialidade da apresentação, induzir em erro os alunos quanto ao teor das diversas ciências, pelo que três horas em média para introduzir à história da formação de cada uma das CS apresentadas, às principais questões e aos debates actuais, nos parece estar abaixo do estrito mínimo necessário ${ }^{5}$.

A realização destes objectivos passa pela adopção de uma estratégia de descrição das ciências e em particular das CS que assenta numa concepção do campo científico que podemos representar num plano definido por duas dimensões: a dimensão que opõe o ponto de vista externo ao interno e a dimensão que diferencia a escala de descrição, ao distinguir contexto restrito e contexto alargado. Uma terceira dimensão intervém quando tomamos em consideração o tempo, ao examinar de que modo as características evidenciadas por cada uma das perspectivas (interna e externa) e cada um dos contextos sociais (restrito e alargado) evoluíram ao longo do processo de formação das disciplinas. É esta orientação que preside à elaboração do "Panorama" (que formaria a primeira parte do Programa da cadeira concebido de acordo com o que foi exposto), que a seguir resumidamente expomos.

\subsection{Uma história social das disciplinas: 0 quadrado das ciências}

Uma descrição externalista, em primeiro lugar, ao considerar a formação e a dinâmica de desenvolvimento das disciplinas enquanto fenómenos sociais (ao mesmo título que a industrialização ou a formaç̧ão das instituições "sociais" (sindicatos, associações operárias, partidos... .), assenta numa polarização que opõe os contextos institucionais restritos (definição de âmbitos de actuação, formas de organização, etc.), aos condicionalismos sociais mais abrangentes.

Uma descrição "internalista" das disciplinas, preocupada com a constituição propriamente intelectual das ciências, identifica necessariamente pelo menos dois pólos, numa oposição homóloga da primeira: teorias e problemas (o vector conceptual donde parte a interrogação da realidade), por um lado e objectos empíricos e métodos (os domínios de fenómenos reais, com os quais se confronta e que defronta a teoria, e os instrumentos que permitem abordá-los), por outro.

3 A partir dos elencos de 9, de 11 ou de 14, etc., que propõem os diversos autores, torna-se possível de compor numerosos diferentes subconjuntos, adaptados aos objectivos e às circunstâncias.

4 Caso frequente em muitas Escolas; mais raro é que a cadeira tenha no máximo duas horas teóricas semanais.

5 É este o processo de cálculo que nos motiva a pensar (ainda o pecado! Venial?) que um volume de duas horas semanais em 15 semanas, ao permitir consagrar 5 a 6 horas a cada disciplina, é 0 ideal. 
Ora, o mínimo que se possa dizer é que os dois planos, que somos obrigados a tratar sucessivamente, não podem ser separados, se quisermos dar conta da estrutura actual do campo científico que, mais ou menos precisamente definido, formam as CS. Embora o seu alcance e as consequências que deles convém retirar sejam diferentes, é certo que ambos são indispensáveis para a construção de uma metodologia de introdução ao campo científico em questão.

A primeira perspectiva associa um ponto de vista diacrónico, que qualificaríamos de genético ou histórico, interessado pelas tentativas de construção de disciplinas e pelo esforço dos grupos que as promovem para impô-las no espaço científico e social, pelas redefiniçōes de perfis, pelas genealogias, pelas heranças e pelos processos contínuos (aliás simultâneos, a partir de uma certo grau de desenvolvimento), de fragmentação e de hibridação, a um ponto de vista estrutural, mais característico de uma sociologia das ciências, interessado pela instauração de espaços científicos, pela constituição de campos especiais, apenas perceptíveis enquanto sistemas de relações entre tentativas ou empreendimentos disciplinares concorrentes e/ou aliados.

A segunda abordagem é de natureza epistemológica, entendida como uma teoria do saber científico e não como uma teoria do conhecimento (ou seja, menos das suas condições de possibilidade que das suas operações efectivas no quadro da prática das ciências).

A necessidade de ambas tem sido reconhecida com regularidade, e seria incorrecto ignorar que a constância do tema e o consenso quanto à problemática que deve presidir à reflexão das CS (e não só delas) sobre si próprias e sobre o espaço científico no qual se inserem, muito se aproxima da figura que, com alguma incerteza quanto ao conceito, mas com notável sucesso, Kuhn chamou "um paradigma": uma maneira normalizada de colocar e tratar certas questões de fundo no interior de um domínio cientíico [Kuhn 1970, Lakatos 1994].

Sem nos aventurarmos no passado mais longe que os anos 1960, de que já sugerimos o carácter de período decisivo na "explosão" das CS na Europa, constatamos que a introdução da epistemologia bachelardiana nas CS marcou uma viragem no desenvolvimento deste grupo de disciplinas. A sua tradução em corpos de princípios de investigação, em métodos de operacionalização dos problemas, em exigências de reflexividade crítica das CS sobre elas próprias (e não só das CS como projectos teóricos mas, pelo menos em idêntica medida, enquanto conjunto de práticas profissionais - o "fício" - e enquanto conjunto de constrangimentos de ordem institucional), instaurou um corpo de conceitos de que somos, hoje ainda - a meio século de distância -, os herdeiros e os utilizadores.

Para esta perspectiva, as CS, como todas as outras ciências, constituem-se de acordo com um duplo movimento: as constantes tentativas de criar novos pontos de vista sobre a realidade e apetrechá-los em conformidade com a natureza dos problemas que se vai construindo e com a natureza dos fenómenos sobre os quais incide o esforço de conhecimento (ou seja, as tentativas para criar novas disciplinas), por um lado; e a confrontação da prática das ciências com a realidade estudada, a avaliação da fecundidade heurística do novo ponto de vista proposto. A este duplo plano conviria acrescentar o plano propriamente institucional, no qual se mede a capacidade dos grupos portadores dos novos programas disciplinares para impô-los no âmbito das universidades, das associações profissionais, das publicações especializadas. 
0 processo de formação das disciplinas científicas actuais, assim como o elenco que constituem na actualidade ganha em ser comparado com o grande número de ciências "falhadas", de disciplinas sem futuro que entretanto foram sendo abandonadas. Se no domínio das ciências médicas e da psicologia a fisiognomia e a frenologia, de que é herdeira a caracteriologia de Lombroso nos fornecem exemplos, no domínio das ciências da matéria conhecemos o exemplo da alquimia. Por seu turno, nas ciências sociais tais exemplos não faltam. 0 projecto de uma "física social" (projecto ao qual Comte opõe o da sua "sociologia", depois de ter ele próprio imaginado uma ciência assim denominada), ou o de uma "psicologia dos povos", ficaram pelo caminho como tentativas sem verdadeiro futuro, ou juntaram-se, no inferno das disciplinas mal sucedidas, à fisiognomia, à craniologia, à raciologia, etc. Ora, se uma "física social" não foi possível (e não é possível enquanto simples aplicação de métodos e conceitos forjados no estudo de um tipo de objectos radicalmente distintos), o reconhecimento das razões de tal impossibilidade importa sobremaneira para entender, a contrario, a fecundidade das disciplinas que sobreviveram à selecção pela crítica e pela confrontação com a realidade.

0 que importa sublinhar é que, se algumas intuições das "ciências falhadas" parecem vir a ser retomadas pelas disciplinas que vieram a ocupar os espaços que as primeiras tentavam delinear, tais ciências mortas nem sempre são proto-ciências ${ }^{6}$, precursoras idóneas mas imperfeitas das disciplinas modernas. Antes, foram primeiro esperanças ilusórias, antes de converter-se em verdadeiros obstáculos epistemológicos no sentido pleno da noção bachelardiana. Mas elas foram também obstáculos institucionais, políticos e sociais à construção de saberes científicos válidos, como o demonstra a história da antropologia, nomeadamente nos casos alemão e francês. R. Mucchielli mostrou a dificuldade científica, decerto, mas também institucional, que as ciências sociais tiveram para se libertarem da prisão conceptual biologista [Mucchielli 1998] e para conquistarem espaços institucionais, nomeadamente universitários, próprios. A sociologia, primeiro com o Durkheim das "Regras do Método sociológico" [Durkheim 1980], a antropologia um pouco mais tarde, tiveram que travar um árduo combate num terreno previamente ocupado pelas teorias do fundamento biológico das diferenças sociais e culturais, pela obsessão da classificação hierarquizada das raças, e pela sistematização de saberes nos quais a "raça" é noção central, por um lado, e pelas falsas "psicologia dos povos" de Wund, ou psicologia dos "caracteres nacionais", por outro. A "raciologia" apoiava-se, por seu turno, numa biologia que, quantificada, reivindicava uma cientificidade acrescida, a "craniologia". Curiosamente, as consequências políticas e sociais que os protagonistas destas "ciências" (as aspas são de hoje, não do seu tempo), entendiam tirar dos seus estudos, não só tiveram uma larguíssima aceitação pelos estados, como foram adoptadas durante quase um século (de meados do século XIX a meados do século XX), como fundamento de políticas de dominação colonial, de intervenção demográfica nos próprios espaços metropolitanos, de eliminação de certas populações. ${ }^{7}$ Escusado será relembrar que de tais ciências

6 Um dos casos em que é possível reconhecer uma intuição que viria a ser validada mais tarde, no âmbito de saberes científicos de estrutura moderna, é o estudo das localizações cerebrais por Gall. Todavia, enquanto Gall permanece prisioneiro da episteme própria da "frenologia", à procura de correspondências entre especializações cerebrais e formas cranianas externas, a problemática moderna foi obrigada a renunciar a tais correlações: a deslocar totalmente o questionamento inicial.

7 É óbvio que o III Reich alemão levou a aplicação de tais teorias a extremos de sistematização; mas elas não são criação sua. Errada é também a ideia segundo a qual o fim da Il guerra mundial e a derrota nazi teriam sido sinónimos de desaparecimento de tais "ciências". Assim, nos EUA e na 
"biológicas", nada resta, senão a certeza que uma teoria com pretensão científica não precisa de ser verdadeira para poder produzir efeitos reais, devastadores, quando adoptada pelos poderes políticos.

\section{4 "Sistema do saber" ou "espaço dos saberes"? Dinâmica das disciplinas, construção de um espaço das ciências do homem e da sociedade}

Duas opções guiam a nossa concepção do campo das CS. A primeira é de renunciar a um entendimento forte do conceito de sistema: não existe uma sistematicidade dos saberes que constituem o domínio das CS (uma organização de conjunto que atribua a cada disciplina e subdisciplina um lugar unívoco nesse mesmo conjunto, e especifique de modo completo as suas relações com todas as outras). A segunda, que restringe a precedente, consiste em reter uma versão fraca de sistema: um campo parcialmente organizado, ou organizado não por um único princípio mas por vários princípios diferentes, eventualmente heterogéneos, com zonas de relações mais ou menos densas. Este espaço dos saberes tem de ser encarado como um espaço multidimensional, no qual as diferentes ciências ocupam lugares relativos distintos consoante a dimensão considerada. Lugares situados segundo um conjunto complexo de coordenadas, os lugares das disciplinas também não são fixos. As fronteiras que separam as disciplinas são pouco nítidas e elas deslocam-se durante o processo de crescimento dos conhecimentos, dando novos contornos aos objectos e aos métodos. Por outro lado, duas tendências opostas, a fragmentação e a hibridação, determinam novos ajustamentos das posições disciplinares no espaço científico.

A fragmentação, que corresponde à tendência para a especialização, resulta de constrangimentos cognitivos evidentes: 0 aprofundamento de conhecimentos sectoriais no interior do campo das disciplinas exigiu a redução do campo fenomenológico observado. Tornou-se cada vez mais difícil absorver e dominar a totalidade da informação disponível sobre objectos de contornos cada vez menos vastos. Por seu turno, a concentraçãa do esforço científico sobre objectos mais restritos aumentou a produtividade do trabalho científico, autoalimentando o processo de modo cumulativo. As ramificações disciplinares que se produziram não são próprias de uma parte apenas do campo científico, a que corresponderia às ciências da matéria e da natureza, mas afectou também as CS, sobretudo nos últimos sessenta anos [Dogan \& Pahre 1990].

0 movimento inverso surge como uma reacção"espontânea", isto é, ditada pelas necessidades práticas da investigação tanto quanto pelos impasses teóricos, e consiste numa série de "cruzamentos de subdisciplinas", na "hibridação ou mestiçagem de especialidades que pertenciam . . . a disciplinas diferentes". Assim, "[c]onsoante a definição adoptada, podemos contar actualmente entre oito e

Suécia, para citar apenas dois exemplos, as políticas "eugenistas", directamente inspiradas da episteme dos raciólogos e/ou da "caracteriologia" frenológica de Cesare Lombroso, continuaram a ser aplicadas até aos anos 1960 de maneira particularmente mortífera (desde a eliminação física dos sujeitos indesejáveis até à sua neutralização neurocirúrgica, à esterilização, etc.). Em França, só nos anos 1950 é que a "antropologia física" de inspiração raciológica veio a ser definitivamente posta em causa, perdendo as posições institucionais que ainda mantinha. 
catorze disciplinas reconhecidas nas ciências sociais. Teoricamente, qualquer ciência social poderia ser miscigenada com todas as outras. ( . . .) Conta-se actualmente mais de uma centena de subdisciplinas híbridas, tendo algumas delas também ascendentes nas ciências naturais" [Dogan \& Pahre 1990].

M. Dogan e R. Pahre distinguem neste duplo processo (especialização/hibridação) várias "gerações", contando com as novas hibridações entre saberes híbridos anteriormente constituídos e com as novas especializações. A importância destas novas associaç̃ões ultrapassa 0 aspecto quantitativo das realidades científicas (número de disciplinas, número de investigadores e de artigos produzidos), pois "nos nossos dias, a maior parte das inovações científicas surgem nas charneiras das disciplinas tradicionais, nas zonas fronteiriças, nos interstícios - sendo o centro das ciências sociais clássicas, por assim dizer, abandonado".

Sem entrar no debate sobre "interdisciplinaridade" e "transdisciplinaridade", formas de associação sempre algo instáveis, que vêm complicar ainda o quadro classificatório das ciências, importa relembrar a importância da circulação de numerosos conceitos de umas ciências para as outras (os "conceitos nómadas" de I. Stengers [1987]), que tendem a constituir um substrato teórico no qual F. Gil [1990] queria ver uma "ciência geral" em formação: "Caminhamos para uma scientia generalis de um novo tipo, estabelecida sobre o saber disciplinar adquirido e que não tenta decerto, como a antiga, responder a todas as questões possíveis. Contudo, os seus problemas, os seus conceitos e as suas regras de validação distinguem-na nitidamente do saber disciplinar: é uma ciência que aspira a uma inteligibilidade genérica".

Que a tendência para a formação de um corpus teórico "nómada" ou transdisciplinar seja ou não uma realidade, é certo que as duas direcções acima indicadas têm que traduzir-se na concepção dos ensinos introdutórios ás CS, fornecendo um panorama, ainda que superficial, dos saberes disciplinares e a iniciação aos conceitos fundamentais tratados numa perspectiva transversal não só ao conjunto das CS, como a um conjunto mais vasto de ciências actuais. 0 primeiro poderia ser comparado a um mapa a pequena escala, de que alguns sectores poderiam ser ampliados pelo estudante no decurso da sua aprendizagem. Os segundos, deveriam ser ferramentas que permitem tanto a entrada nas disciplinas, como o movimento no espaço mais vasto do campo científico em geral.

\subsection{Enciclopédia impossível, um percurso "enciclopédico" indispensável}

Estamos hoje, mais longe que nunca da possibilidade de construir uma Enciclopédia resumindo o estado actual dos conhecimentos científicos; e nem a restrição do projecto a um domínio parcelar, como os das ciências que nos ocupam, seria suficiente para torná-lo menos utópico. A tendência para a acumulação de conhecimentos e para a concomitante explosão das especialidades afirmou-se, para o conjunto das disciplinas científicas, desde o período entre as duas guerras mundiais, e sofreu uma aceleração decisiva após a segunda; enfim, as CS conheceram um desenvolvimento exponencial no último terço do século passado. Não só o conhecimento aprofundado de todas as ciências ditas sociais se tornou uma evidente impossibilidade, como, e esse será talvez o facto novo que as últimas décadas 
produziram, deixou de ser possível dominar de modo suficiente a totalidade dos subdomínios nos quais as grandes disciplinas se foram dividindo. Nenhum sociólogo conhece (ainda que de modo apenas parcial), os resultados e os debates em curso em todos os ramos especializados da sociologia, que se contam às dezenas, o mesmo acontecendo fatalmente com os seus colegas psicólogos, historiadores, economistas, etc.

Curiosamente, é a própria proliferação dos conhecimentos e das especialidades resultante do desenvolvimento científico que torna mais necessário um percurso de cariz enciclopédico, tratando-se de introduzir os estudantes ao estudo das ciências em geral e das (S em particular. Com efeito, a expansão e a multiplicação das especialidades produz uma dificuldade inédita, ao justapor uma maior segurança dos conhecimentos por um lado, com uma separação cada vez mais profunda entre objectos, problemas e linguagens, tornando difíil senão a síntese (utopia fora de alcance), pelo menos a comunicação entre ciências e cientistas de disciplinas diferentes. Mas por outro lado, torna-se doravante evidente a que ponto a ignorância dos campos conexos é não só um factor limitativo decisivo para a renovação das problemáticas no próprio interior da cada disciplina, como constitui um obstáculo de primeira importância para a iniciação dos futuros cientistas. Sem uma base de cultura científica no domínio das ciências sociais, simultaneamente alargada e sólida, torna-se impossível entender o que está em jogo, do ponto de vista da produção de conhecimentos como do ponto de vista da sua utilidade social, na cultura das ciências.

Deste modo, um percurso de cariz enciclopédico pelo domínio das CS (ainda que aceitando as restrições que dissemos), é uma exigência de base para qualquer iniciação a uma qualquer das CS; e já veremos que algo de semelhante se verifica no que respeita à formação dos futuros cientistas de outros domínios.

\section{Conclusão: Um caminho difícil, meta-conhecimento do social}

Se a unificação do campo das CS, entendida como a formulação de problemas de fundo susceptíveis de interessar um conjunto alargado de CS, e como programas científicos de alto nível de abstracção podendo e devendo mobilizar as aquisições das disciplinas especializadas, nos parece estar na ordem do dia, é porque a unidade se nos apresenta no momento actual de modo radicalmente distinto do que assumia nos primórdios. Unificação com ambiç̧ões limitadas (mais consciente dos seus limites), unificação como processo de síntese colectivamente assumido, tal nos parece ser o horizonte. Bem diferente, por conseguinte, do que presidia à postulação de uma unidade a priori, determinada pela simples construção de um sistema das ciências por vir, como o que o positivismo comteano pretendia instaurar. Na realidade, o "terrorismo unitário" de A. Comte "contribuiu para criar obstáculos ao aparecimento de uma ciência social autónoma em França" [Durand \& Weil 1989: 28]: a unidade das ciências impunha uma estrutura hierárquica prévia a um campo cujos elementos estavam por criar.

0 positivismo traçava uma organização unificada e distribuía lugares, atribuições para qualquer desenvolvimento futuro: era uma ordem a priori, que viria a constituir uma prisão para o espírito 
científico. A fase actual parte da constatação simultânea de formidáveis desenvolvimentos locais, parcelares, no seio das especialidades, e de uma desordem também ela formidável. A ordem relativa que pode emergir de uma unificação no futuro próximo mais não será que a sistematização das grandes questões para as quais várias respostas parciais (sólidas, fundamentadas em dados empíricos mais numerosos, apoiadas em métodos mais fráveis), existem desde já. De certo modo, tal processo de unificação partirá das convergências entre disciplinas distintas, ou, se preferirmos, da convergência das descobertas efectuadas de modo independente e até em ordem dispersa, pelas diferentes disciplinas.

Bem diferente é, como vemos, o contexto no qual a ambição unificadora se manifesta hoje em dia, e também as modalidades segundo as quais se pretende promovê-la. As Ciências Sociais, enquanto integradoras dos saberes, são ao mesmo tempo um campo científico específico com objectos próprios como o reclamava Durkheim, e uma janela sobre a constituição desses corpos de conhecimentos socialmente organizados que chamamos "ciências"

\section{Referências bibliográficas}

AUGÉ, M.

1984: "Ordre biologique, ordre social: la maladie forme élémentaire de l'événement". M. Augé and C. Herzlich, pp. 35-91 DAVID, A.; A. HATCHUEL et al.

2000: Les nouvelles fondations des sciences de la gestion. eléments d'épistémologie de la recherche en management. Paris: Vuibert

DOGAN, M. \& R. PAHRE

1990: Les sciences sociales: segmentations et croisements. Encyclopaedia Universalis, Paris, Symposium, no 2, pp. 1119-1126

DURAND, J.-P. \& E. WEIL

1989: Sociologie contemporaine, Paris: Vigot

DURKHEIM, E.

1980: As regras do método sociológico, Lisboa: Presença

FIL, F.

1990: "Post-scriptum”, Encyclopaedia Universalis, Paris, Symposium, no 2, pp. 1699-1732

KUHN, T.S.

1970: "Logic of Discovery or Psychology of Research?", in: I. Lakatos \& A. Musgrave, 1970, pp. 1-23

LAHIRE, B. (ed.)

2002: À quoi sert la Sociologie?, Paris: La Découverte

LAKATOS, I.

1994: Historie et méthodologie des sciences, Vendôme: Presses Universitaires de France

MAUGERI, S. (ed.)

2001: Délit de gestion, Paris: La Dispute

MUCCHIELLI, L.

1998: La découverte du social. Naissance de la sociologie en France, Paris: La Découverte

RESENDE, J. M.

2003: "Para que serve a Sociologia no contexto da nossa modernidade inacabada?", Ciclo de Conferências Sociologia, Ciência e Profissão, Porto: Faculdade de Letras da Universidade do Porto, Associação Portuguesa de Sociologia, pp. 1-4 
STENGERS, I. (ed.)

1987: D'une science à l'autre. Des concepts nomades, Paris: Seuil

\section{Artigo pedido ao autor}

Recebido a: 8/Julho/2013

Aceite para publicação: 19/Agosto/2013

\section{Title}

What place and role for the Social Sciences in a world under deep and turbulent changes?

\section{Abstract}

The author interrogates the place of the Social Sciences (SS) in a world that increasingly grants an absolute privilege to techno-science, "Big Science", and its technological applications. The exposed thesis is that the changes affecting the present world, because of their depth and the speed at which they occur, set a challenge to our societies that only SS can sustain: the understanding and management of processes of social change and its consequences. To meet the challenge, the SS must develop a dual scientific strategy: at the epistemological level, they ought to develop the concepts and tools for research; on the institutional level, including the higher academic levels, there should be a thorough learning of SS, giving them a full place in the curricula. The objectives will be the founding of a new "general culture" and grounded citizenship, and producing operational knowledge for the benefit of the political, economic, social and human development of our societies.

\section{Key-words}

Social Sciences; Change; Teaching; Curricula; Epistemology; Research; Policy 